\title{
Elective gangrene of the corpus spongiosum of idiopathic origin: A case report
}

\author{
Youssef Kharbach, MD; Somuah Tenkorang, MD; Amine Bouchikhi, MD; Soufiane Mellas, MD, PhD; \\ Jalaleddine El Ammari, MD, PhD; Mohammed Fadl Tazi, MD, PhD; Abdelhak Khallouk, MD, PhD; \\ Mohammed Jamal El Fassi, MD, PhD; Moulay Hassan Farih, MD, PhD
}

Hassan II Teaching Hospital, Department of Urology, Morocco

Cite as: Can Urol Assoc J 2014;8(11-12):e934-7. http://dx.doi.org/10.5489/cuaj.2316 Published online December 15, 2014.

\section{Abstract}

Penile gangrene is rare and associated with significant morbidity and mortality. It can be dry or wet. Treatment for dry gangrene is based on surgery, watchful waiting allowing spontaneous amputation of necrotic tissue or revascularization. It often depends on the general condition of the patient. We report a case of a 54-year-old patient with no significant medical history who presented with necrosis of the glans penis. Upon surgical exploration, we found an elective necrosis of the entire corpus spongiosum for which partial penectomy was performed. No etiology was found. To our knowledge, this is the first such case to be reported in the literature.

\section{Introduction}

Penile gangrene is rare and associated with significant morbidity and mortality. ${ }^{1}$ Its management depends on whether it is dry or wet gangrene. Treatment can be conservative or surgical, and often depends on the patient's general condition. We report the case of a 54-year-old patient with no significant medical history who presented with dry gangrene of the penis and underwent partial penectomy.

\section{Case report}

A 54-year-old patient presented with a localized induration of the penis glans, which turned black causing a rapid progressive dysuria 5 days before his consultation. He had no significant medical history, particularly no history of diabetes, chronic renal disease, cardiovascular risk factors, recent trauma, or toxic habits,

Upon clinical examination, we found a conscious patient with stable vital signs. He had acute urine retention. He had dry gangrene of the penis glans with a completely closed urethral meatus (Fig. 1); this made it impossible to drain urine using an intrauthral catheter. Thus a suprapubic catheter was placed. The testes were normal in appearance and consistency. His laboratory tests revealed a fasting glucose of $1.01 \mathrm{~g} / \mathrm{L}$, creatinine of $11 \mathrm{mg} / \mathrm{L}$, hemoglobin of $12 \mathrm{~g} / \mathrm{L}$, and white blood cell count of $9800 / \mathrm{mm}^{3}$. His urine culture was negative and tests for possible coagulopathy were also negative.

It was impossible to determine the extent of necrosis using a flexible urethroscopy. Doppler ultrasonography of the penis showed a well-vascularized corpora cavernosa with absence of flow in the corpus spongiosum. Magnetic resonance angiography (MRA) implementation could not help as its spatial resolution was not sufficient to explore the arteries of the penis.

In the absence of etiological factors, we initially concluded that the patient had idiopathic necrosis of the glans and we decided to operate.

Surgical exploration found complete necrosis of all the corpus spongiosum up to its root (Fig. 2). The corpora cavernosa were intact. We performed a complete necrosectomy and created a perineal urethrostomy (Fig. 3, Fig. 4).

Postoperative course was simple (Fig. 5). The patient had satisfactory continence. He underwent follow-ups during and after hospitalization with a psychologist to manage the psychological impact of his condition.

Pathology finding showed inflammatory tissue with no signs of malignancy. To our knowledge, this is the first reported case of an elective gangrene of the corpus spongiosum in which commonly known etiologies were eliminated.

\section{Discussion}

Penile gangrene is a rare entity that can manifest in 2 forms: dry or wet. Each form requires different treatments. ${ }^{1,2}$

Wet gangrene, also known as infectious necrosis of the penis, is comparable to Fournier's gangrene or necrotizing fasciitis. This is an emergency, as the time between diagnosis 


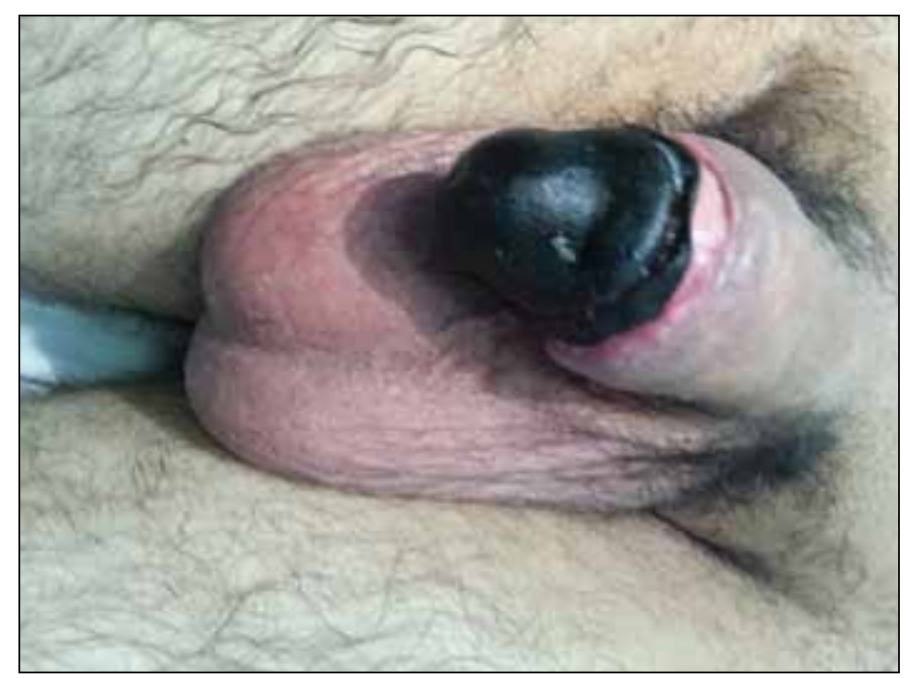

Fig. 1. Dry gangrene of the glans penis.

and treatment significantly affects morbidity and mortality and the disease can rapidly progress to sepsis. ${ }^{3}$ Its origin is often related to the urethra (in the case of a stricture disease), the rectum (in the case of perianal abscesses, fissures, and fistula), genitourinary trauma or instrumentation. The source of infection is identified in $95 \%$ of cases. ${ }^{1}$

Dry gangrene often originates from ischemia ${ }^{3}$ or a venoocclusive disease. ${ }^{4}$ It is often secondary to diabetes or endstage renal disease leading to secondary hyperparathyroidism. This situation will lead to calciphylaxis of the penile arteries and thus a reduced blood flow. ${ }^{1,5}$ Less frequent

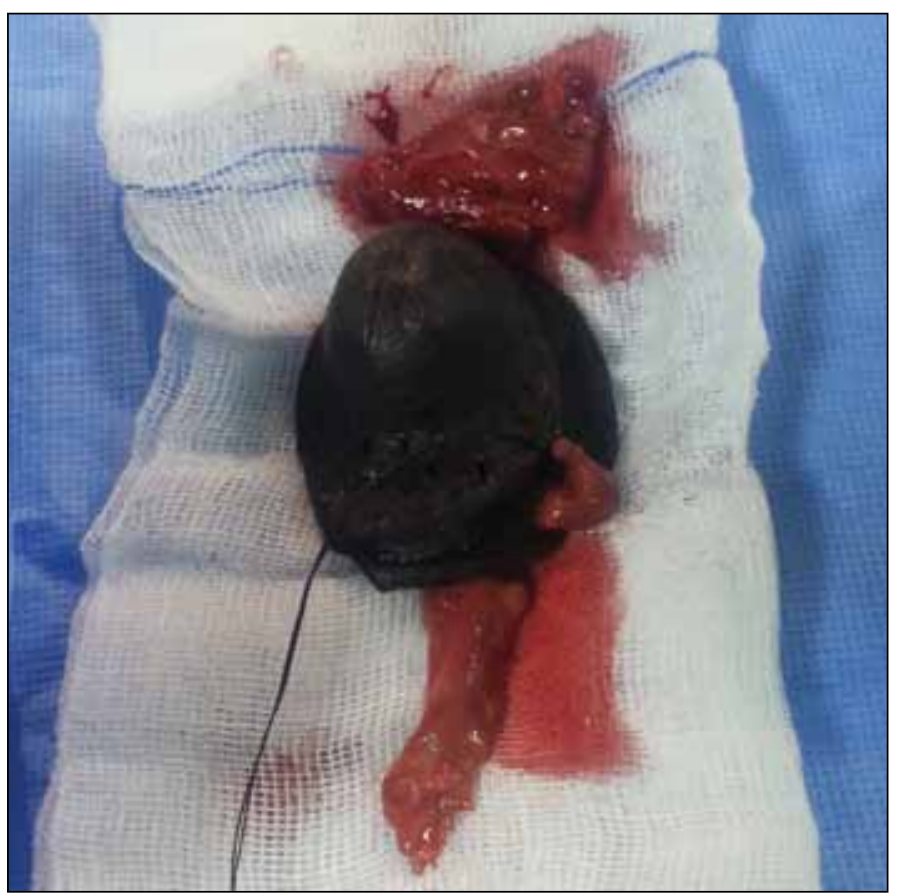

Fig. 3. Pathology specimen.

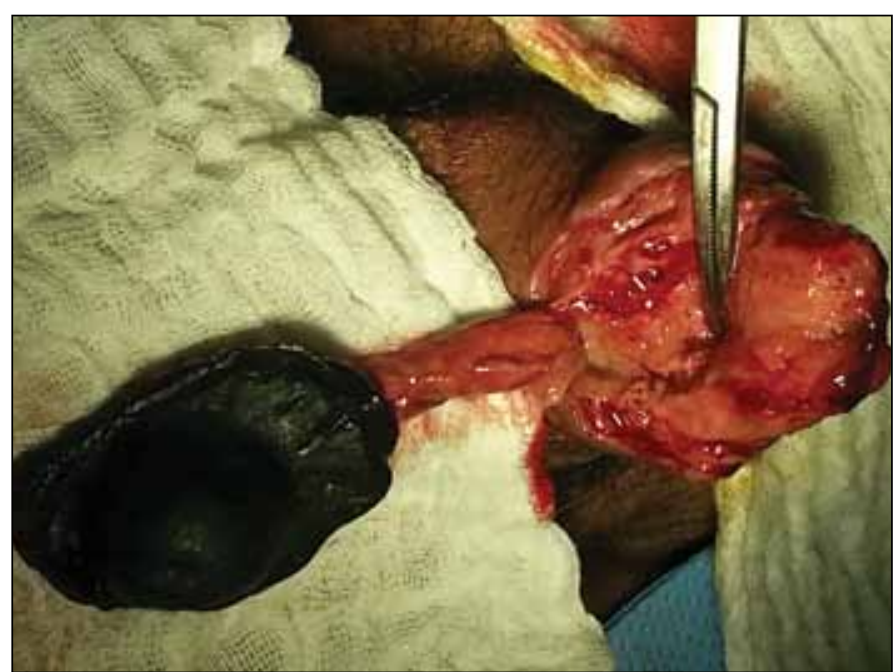

Fig. 2. Perioperative aspect.

causes include tourniquet effect, priapism, venous thrombosis, anticoagulant treatment and injection of heroin in the femoral vessels, ${ }^{1,5}$ or penile prosthesis. ${ }^{4}$

Arterial vascularization of the penis is provided by 3 branches of the internal pudendal artery: dorsal artery, cavernous artery, and the Bulbourethral artery. Physiological variations include an extra penile alternative arterial system from the external obturator or iliac arteries; ${ }^{6}$ this important vasculature explains the rarity of ischemic gangrene of the penis. However, this is a condition that occurs in the context of vascular disease and diabetic patients who develop gangrene of the penis have a high mortality rate. ${ }^{7}$

Doppler ultrasound may help in choosing the right treatment. Watchful waiting or revascularization may be employed in patients with very small well-circumscribed lesions with residual vascular flow. ${ }^{8}$ However, the absence

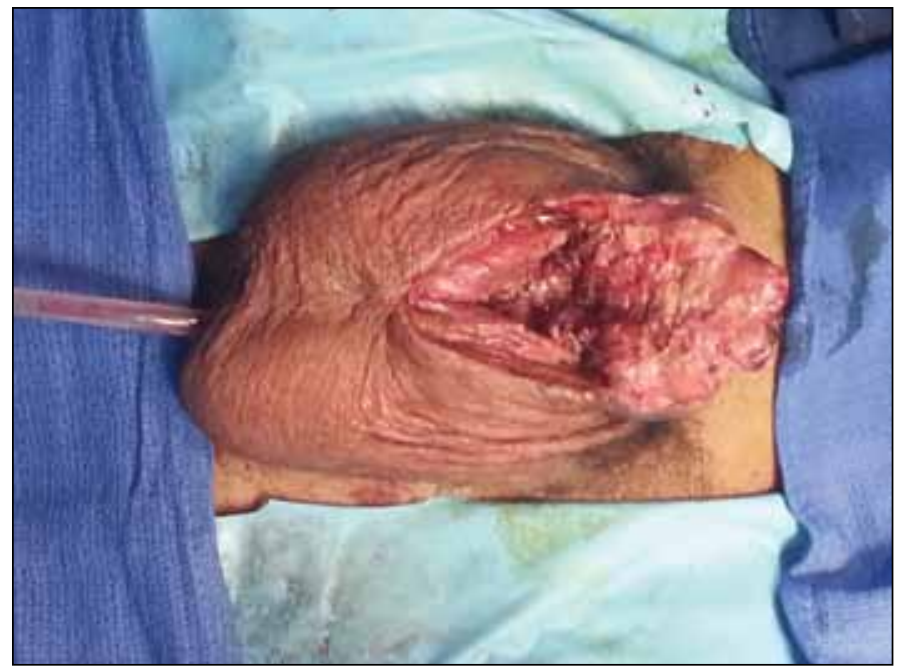

Fig. 4. Aspect after necrosectomy. 


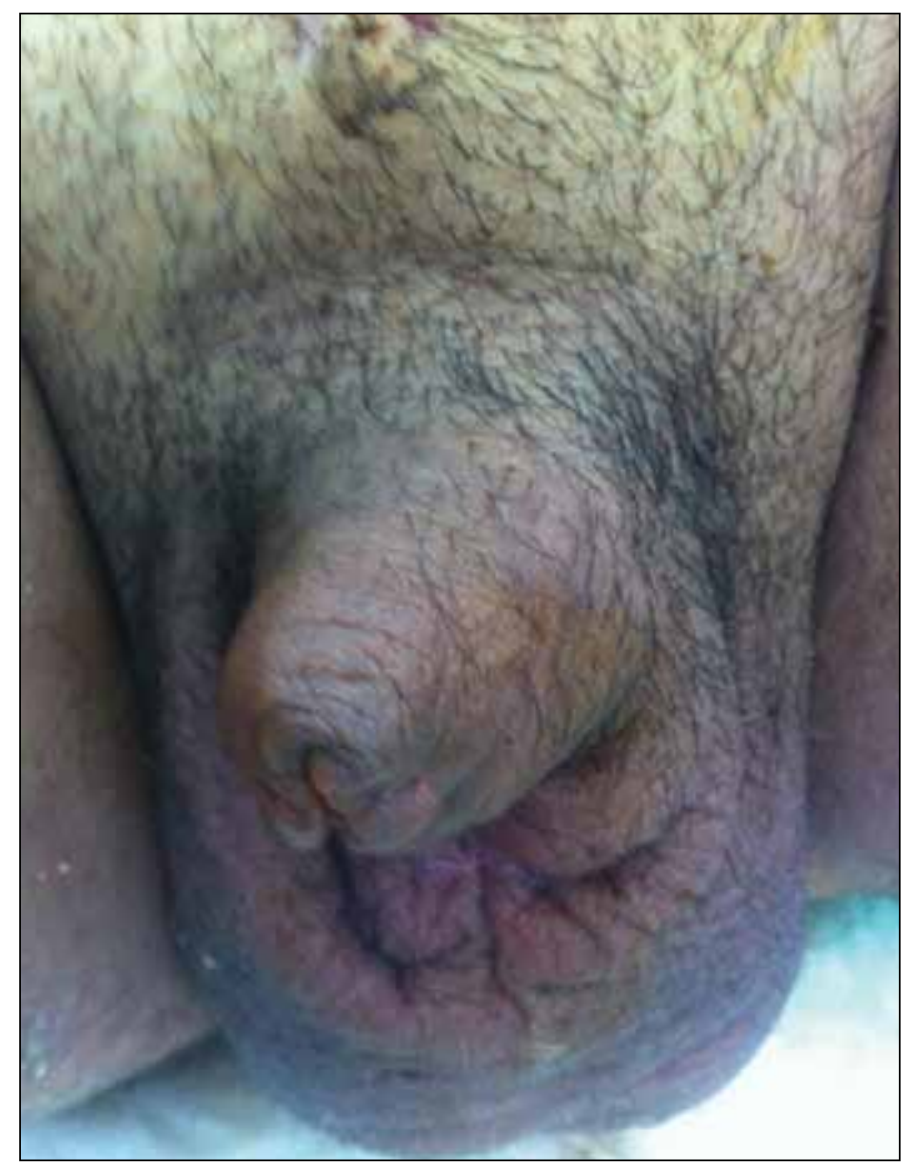

Fig. 5. Aspect 15 days after surgery.

of blood flow suggests surgical removal of dead tissues, which may justify a total or partial penectomy using ultrasound to determine the extent of necrosis.

Treatment for dry gangrene is largely based on surgery; watchful waiting may be used to anticipate any spontaneous amputation of necrotic tissues or revascularization. ${ }^{1}$ Conservative treatment is reserved for cases with small welldefined lesions ${ }^{2,9}$ or in patients with a high risk of morbidity and mortality associated with generalized arterial disease. ${ }^{10}$

Conservative treatment is often followed by surgical treatment by performing partial penectomy due to infection, liquefaction. or progression of gangrene. ${ }^{2}$ Some authors recommend circumcision when conservative treatment is undertaken to allow better monitoring and dry healing of wounds. ${ }^{4,9}$ Surgical treatment options include dorsal slits, supra-pubic cystostomy, and urethral catheterization. In patients with voiding difficulties, debridement and partial or full penectomy is suggested. ${ }^{4}$ These surgical procedures can be performed independently or in sequence, considering the patient's comorbidities and wound conditions. ${ }^{4,9}$

Penile revascularization is an option in patients. Treatment is determined based on selective angiography of the iliac arteries. Few cases of penile revascularization for ischemia using arterialization of the deep dorsal vein have been reported. In other cases inferior epigastric artery implantation or saphenous vein graft from the femoral artery into the corpuscavernosum has been performed. ${ }^{8}$

Dry gangrene is an irreversible process; the ischemic tissues will lead to thrombus formation and thus extension of gangrene. So, early partial penectomy and treatment of underlying conditions can prevent infection and will retain more length of the penis and improve the quality of life. ${ }^{4}$

Several authors have reported that the alleged preoperative extension of gangrene is often underestimated compared to intraoperative findings. ${ }^{4}$

Even though no signs of secondary infection were observed and the gangrene seemed to be localized on the glans penis in our case, we opted for partial penectomy as our patient was young. This was intended to prevent possible complications, such as secondary infections or extension of necrosis. Moreover, we had no other means to determine the extent of the gangrene.

Intraoperative findings showed more extensive necrosis than expected from the gangrene of the skin, with ischemic changes reaching deep into the perineal area of the corpus spongiosum. Literature review showed that elective gangrene of the corpus spongiosum is very rare and in our case no etiology could be found.

\section{Conclusion}

Gangrene of the penis is rare and often associated with an irreversible ischemic process. Its therapeutic management is mainly dependent on the patient's general condition and the underlying pathology. Early partial penectomy can limit the spread of gangrene, inhibit infection, and improve morbidity and mortality.

Competing interests: Authors declare no competing financial or personal interests.

This paper has been peer-reviewed.

\section{References}

1. Singh V, Sinha RJ, Sankhwar SN. Penile gangrene: A devastating and lethal entity. Saudi J Kidney Dis Transpl 2011;22:359-61

2. Gillitzer $R$, Franzaring $L$, Hampel $C$, et al. Complete gangrene of penis in patient with arterial vascular disease. Urology 2004;64:1231.e4-6.

3. Weiner DM, Lowe FC. Gangrene of the male genitalia. AUA Update series 1998. Lesson 6, Vol XVII, 42-7.

4. Chiang IN, Chang SJ, Kuo YC, et al. Management of ischemic penile gangrene: Prompt partial penectomy and other treatment options. J Sex Med 2008;5:2725-33. http://dx.doi.org/10.1111/i.17436109.2008.00894.x

5. Lowe FC. Gangrene of the male genitalia. In: Operative Urology. F.F. Marshall, editor. Philadelphia: PA. W.B. Saunders Co, Ch. 50, 1991;377-96.

6. Lue TF. Erectile dysfunction. N Engl J Med 2000;342:1802-13. http://dx.doi.org/10.1056/ NEJM200006153422407 
7. Agarwal MM, Singh SK, Mandal AK. Penile gangrene in diabetes mellitus with renal failure: A poor prognostic sign of systemic vascular calciphylaxis. Indian J Urol 2007;23:208-10. http://dx.doi. org/10.4103/0970-1591.32081

8. Tu D, Rashid M, Orihuela E, et al. Arterialization of deep dorsal vein of penis for penile ischemia. Urology 2005;65:174. http://dx.doi.org/10.1016/i.urology.2004.07.009

9. Harris CF, Mydlo JH. Ischemia and gangrene of the penis. J Urol 2003;169:1795. http://dx.doi. org/10.1097/01.ju.0000057796.64080.3a
10. Mydlo JH, Harris (F, Brown JG. Blunt, penetrating and ischemic injuries to the penis. J Urol 2002;168(4 Pt 1):1433-5. http://dx.doi.org/10.1016/S0022-5347(05)64467-9

Correspondence: Dr. Youssef Kharbach, Hassan II Teaching Hospital, Department of Urology, Morocco; dr.kharbach@gmail.com 